\title{
Aerobic and Anaerobic Bacterial Isolates on the Surface and Core of Tonsils from Patients with Chronic Tonsillitis
}

\author{
Meera Niranjan Khadilkar, ${ }^{1}$ Nitin Ankle, ${ }^{1}$ Sheetal Harakuni ${ }^{2}$
}

\section{Introduction}

\section{ABSTRACT}

Controversy regarding treatment of tonsillitis based on throat culture report still persists. If surface culture is a determinant of bacteriology of the core, then rational therapy could be aimed at organisms cultured by surface swab.

Materials and Methods

A Cross-sectional study was conducted on 100 patients of chronic tonsillitis who underwent tonsillectomy. Tonsil surface and core swabs were studied for aerobic and anaerobic growth.

$\underline{\text { Results }}$

Seventy-three percent patients had aerobic growth on tonsil surface and $74.2 \%$ in tonsil core. Staphylococcus aureus was the commonest aerobic bacteria isolated. Anaerobic growth was present in $44.4 \%$ patients on tonsil surface, and $48.4 \%$ in core. Porphyromonas sp. was the commonest anaerobic bacterium isolated.

Discussion

There was no statistically significant difference between aerobic and anaerobic bacteria found in tonsil surface and core. Conclusion

Throat swabs adequately represent core pathogen, and are dependable in detecting bacteriology of chronic tonsillitis. $\underline{\text { Keywords }}$

Tonsillitis; Bacteria, Aerobic; Bacteria, Anaerobic.

$\mathrm{T}$ onsillitis remains a frequently occurring clinical problem, affecting children and adults. Although treated everyday, the controversy regarding treatment based on throat culture report still persists. Chronic tonsillitis is not only clinically suspected, but has to be supported by bacteriological and patho-anatomical considerations. Empirical treatment of chronic tonsillitis patients cannot be based on bacteriological profile of surface. The bacterial profile obtained by swabbing the surface, may be colonizers only. If surface culture is a determinant of bacteriology of the core, then rational therapy could be aimed at organisms cultured by surface swab. This study was planned to assess the relationship of aerobic and anaerobic bacterial isolates on the surface and in the core cultures from recurrently infected and inflamed tonsils.

\section{Materials and Methods}

A cross-sectional study was conducted on hundred patients of chronic tonsillitis, who attended the Out Patient Department of ENT, from January to December 2014, who underwent tonsillectomy, were taken for the study after obtaining written informed consent. Patients with history of more than 3 episodes of tonsillitis for a minimum of 6 months, with no relief of symptoms, where selected for tonsillectomy. Patients were treated with broad-spectrum antibiotics before surgery. Patients

1 - Department of ENT, Jawaharlal Nehru Medical College, KLE University, Belgaum

2 - Department ofMicrobiology, Jawaharlal Nehru Medical College, KLE University, Belgaum

Corresponding author:

Dr Meera Niranjan Khadilkar

email: musicnmee@gmail.com 
with tonsillar malignancy and those who failed to give consent were excluded. The study was approved by Institutional Ethics Committee.

Two swabs were procured from the tonsillar surface intraoperatively by rotating sterile cotton wool swabs over the surface of the tonsil, avoiding any other part of the oropharynx, before tonsillectomy. The tonsillar specimen obtained after surgery was immediately dipped into povidone iodine solution for half a minute and then rinsed in sterile saline solution. It was sectioned into two parts following thorough asepsis. Two sterile swabs were applied to the inner surface of the sectioned tonsil, without coming in contact with the outer surface. One swab from each pairs was transported in thioglycollate medium for anaerobic culture. The four samples were transported to the Microbiology laboratory for culture. The samples were processed for isolation of aerobic bacteria and anaerobic bacteria as per the standard protocol. ${ }^{1,2}$ Statistical analysis was done to determine percentage and the significance between the aerobic and anaerobic isolates from surface and core of the infected tonsil by application of Chi-square test and Fischer Exact test.

\section{Results}

Chronic tonsillitis most commonly (44\%) affected the adolescent age group (11-20 years). There was a slight female predilection in chronic tonsillitis with females comprising $53 \%$ and males $47 \%$. Twenty (20\%) patients had grade 2 tonsillar hypertrophy, 66 (66\%) patients had grade 3 tonsillar hypertrophy, and $14(14 \%)$ patients had grade 4 tonsillar hypertrophy; 37\% patients had adenoids. Majority of patients (73\%) with chronic tonsillitis manifested with bilateral jugulodigastric lymphadenopathy. Indication for tonsillectomy in 63 $(63 \%)$ patients was chronic tonsillitis and in $36(36 \%)$ patients was chronic adenotonsillitis. One (1\%) patient had chronic adenotonsillitis with bilateral chronic otitis media (COM). Eighty-three $(83 \%)$ patients had parenchymatous tonsillitis, while $17(17 \%)$ patients had follicular tonsillitis.

Sixty-two (62\%) and sixty-three patients (63\%) patients had bacterial growth on tonsil surface and core respectively. Fifty-four out of $62(87 \%)$ and 57 out of $63(90 \%)$ patients had aerobic growth on tonsil surface and tonsil core respectively. Thirty-seven out of 54 $(69 \%)$ patients had aerobic growth in tonsil surface as well as tonsil core; of which $29(78 \%)$ patients had same aerobic growth on tonsil surface as well as in tonsil core. The remaining 18 patients had aerobic growth in either tonsil surface or in core. Eight out of 54 (15\%) patients had polymicrobial aerobic growth on tonsil surface, 9 out of 57 (16\%) patients had polymicrobial aerobic growth in tonsil core.

Staphylococcus aureus was the commonest aerobic isolate in surface culture $(40.7 \%)$ followed by Streptococcus pyogenes (18.5\%), Klebsiella pneumonia (9.3\%), Streptococcus pneumoniae, Pseudomonas aeruginosa, Enterococcus sp. (7.4\%), Citrobacter sp. (3.7\%), and Klebsiella oxytoca, Escherichia coli, Acinetobacter $(1.9 \%$ each). In core cultures too, Staphylococcus aureus and Streptococcus pyogenes were the commonest aerobes isolated $(33.3 \%$ \& $21.1 \%$ respectively), followed by Streptococcus pneumoniae (14.0\%), Klebsiella pneumoniae (10.5\%), Pseudomonas aeruginosa $(7.0 \%)$, and Neisseria catarrhalis, Escherichia coli, Acinetobacter sp. (1.8\% each). No statistical difference between surface and core cultures was seen. (Table I).

Twenty-nine out of $62(47 \%)$ and 30 out of $63(48 \%)$ patients had anaerobic growth on tonsil surface and core respectively. Twenty-two out of 29 (76\%) patients had anaerobic growth on tonsil surface as well as in tonsil core, of which 13 patients had the same growth on tonsil surface as well as core. The remaining 7 patients had anaerobic growth in either tonsil surface or in core. One out of $29(3 \%)$ patients had polymicrobial anaerobic growth on tonsil surface. No patients had polymicrobial anaerobic growth in tonsil core.

Porphyromonas sp. was the commonest anaerobe isolated in both surface and core cultures $(41.4 \%$ and $33.3 \%$ respectively) in the present study. Bacteroides fragilis (17.2\%), Prevotella intermedia, Prevotella loescheii $(10.3 \%$ each), Prevotella melaninogenica $(6.9 \%)$ were the other anaerobic isolates in surface cultures. Fusobacterium sp., Peptostreptococcus sp., Bilophila sp., Actinomycetes concomitans (3.4\%) were the uncommon anaerobic bacteria isolated 
exclusively in surface cultures. The core cultures also isolated Bacteroides fragilis (26.7\%), Prevotella

Table I: Comparison of Aerobic Bacteria in Tonsil surface and core

\begin{tabular}{|c|c|c|c|c|c|}
\hline 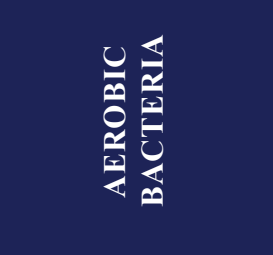 & 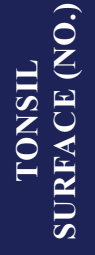 & 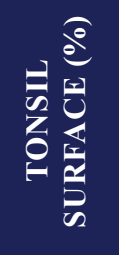 & 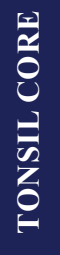 & 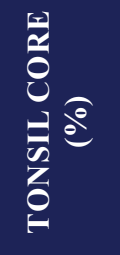 & $\begin{array}{l}\frac{15}{2} \\
\frac{5}{2} \\
\frac{1}{2}\end{array}$ \\
\hline $\begin{array}{c}\text { Staphylococcus } \\
\text { aureus }\end{array}$ & 22 & $40.7 \%$ & 19 & $33.3 \%$ & 0.693 \\
\hline $\begin{array}{l}\text { Streptococcus } \\
\text { pyogenes }\end{array}$ & 10 & $18.5 \%$ & 12 & $21.1 \%$ & 0.739 \\
\hline $\begin{array}{l}\text { Streptococcus } \\
\text { pneumoniae }\end{array}$ & 4 & $7.4 \%$ & 8 & $14.0 \%$ & 0.413 \\
\hline $\begin{array}{l}\text { Klebsiella } \\
\text { pneumoniae }\end{array}$ & 5 & $9.3 \%$ & 6 & $10.5 \%$ & 0.824 \\
\hline $\begin{array}{c}\text { Klebsiella } \\
\text { oxytoca }\end{array}$ & 1 & $1.9 \%$ & $\mathbf{0}$ & $0 \%$ & 0.486 \\
\hline $\begin{array}{l}\text { Neisseria } \\
\text { catarrhalis }\end{array}$ & $\mathbf{0}$ & $0 \%$ & 1 & $1.8 \%$ & 0.486 \\
\hline Escherichia coli & 1 & $1.9 \%$ & 1 & $1.8 \%$ & 1 \\
\hline $\begin{array}{l}\text { Pseudomonas } \\
\text { aeruginosa }\end{array}$ & 4 & $7.4 \%$ & 4 & $7.0 \%$ & 0.774 \\
\hline $\begin{array}{l}\text { Citrobacter } \\
\text { freundii }\end{array}$ & 2 & $3.7 \%$ & 3 & $5.3 \%$ & 0.949 \\
\hline Acinetobacter sp. & 1 & $1.9 \%$ & 1 & $1.8 \%$ & 1 \\
\hline Enterococcus sp. & 4 & $7.4 \%$ & 2 & $3.5 \%$ & 0.327 \\
\hline TOTAL & 54 & $100 \%$ & 57 & $100 \%$ & \\
\hline
\end{tabular}

melaninogenica (20.0\%), Prevotella intermedia (16.7\%) and Fusobacterium sp. (3.3\%). There was no statistical

Table II: Comparison of Anaerobic Bacteria in Tonsil surface and core.

\begin{tabular}{|c|c|c|c|c|c|}
\hline 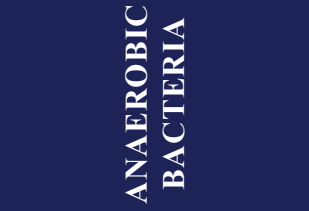 & 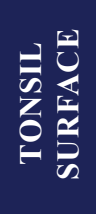 & 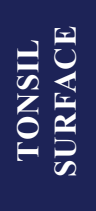 & 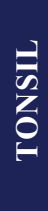 & 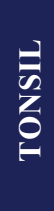 & $\frac{5}{3}$ \\
\hline Porphyromonas sp. & $\mathcal{I}$ & $\frac{\partial_{\dot{\theta}}^{\ominus}}{\dot{\nabla}}$ & 윽 & हैं & ָ̃ \\
\hline Bacteroides fragilis & n & 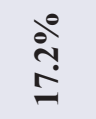 & $\infty$ & i̊ & ָ̃ \\
\hline $\begin{array}{l}\text { Prevotella } \\
\text { intermedia }\end{array}$ & $m$ & 仓̊? & n & $\frac{\theta_{0}^{\circ}}{0}$ & 犬ั? \\
\hline $\begin{array}{c}\text { Prevotella } \\
\text { melaninogenica }\end{array}$ & $\sim$ & बें & 6 & 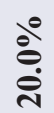 & 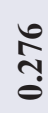 \\
\hline Prevotella loescheii & $m$ & $\ddot{i}_{0}^{\circ}$ & 0 & $\stackrel{\circ}{\ddot{\theta}}$ & $\stackrel{N}{\Xi}$ \\
\hline Fusobacterium sp. & - & $\stackrel{\dot{\theta}^{\ominus}}{\dot{v}}$ & - & लें & $\stackrel{8}{8}$ \\
\hline $\begin{array}{l}\text { Peptostreptococcus } \\
\text { sp. }\end{array}$ & - & 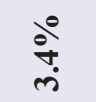 & 0 & $\stackrel{\stackrel{0}{\theta}}{\theta}$ & बें \\
\hline Bilophila sp. & - & $\stackrel{\partial}{\dot{\theta}}$ & 0 & $\stackrel{\stackrel{0}{\ominus}}{\theta}$ & ஓें \\
\hline $\begin{array}{l}\text { Actinomycetes } \\
\text { concomitans }\end{array}$ & - & $\stackrel{\dot{\theta}^{\ominus}}{\dot{m}}$ & 0 & $\stackrel{\stackrel{0}{\theta}}{\theta}$ & ஓें \\
\hline TOTAL & ลิ & $\stackrel{\grave{\theta}}{\theta}^{\circ}$ & లి & $\stackrel{\ominus}{\stackrel{\theta}{\theta}}$ & \\
\hline
\end{tabular}


significant difference between the anaerobic bacteria found in tonsil surface and core. (Table II).

\section{Discussion}

Tonsillitis is a common problem that affects children between the ages of 5-10 years, and is often treated inadequately or inappropriately with antibiotics. This often results in persistent infection with resistant aerobic and/or anaerobic bacteria leading to recurrent attacks of infection and eventually chronic tonsillitis. This condition also affects adults and rarely, the elderly. The resultant chronic inflammation and/or enlargement of the tonsils cause considerable morbidity requiring therapeutic surgical intervention.

Our study showed that adolescents were more affected $(44 \%)$ and there were more females than males (sex ratio of 1:1.12). Similar age incidence was observed in many of the previous studies. ${ }^{3,4,5,6,7,8}$ However the gender incidence was more in men in many of the previous studies.

Majority of the patients who sought surgical intervention had grade 3 tonsillar hypertrophy $(66 \%){ }^{9}$ In $37 \%$ of patients, adenoids were present along with enlarged tonsils, which was comparable to the study by Hadi and co-authors. ${ }^{10}$ Majority of patients (73\%) with chronic tonsillitis manifested with bilateral jugulodigastric lymphadenopathy. Chronic tonsillitis was the major indication for surgery in $63 \%$ of patients followed by chronic adenotonsillitis in $36 \%$. Chronic adenotonsillitis with bilateral chronic otitis media was seen in only $1 \%$. The study group of Hadi and coauthors had more number of cases with adenotonsillitis than tonsillitis alone. ${ }^{10}$

In the present study, bacterial growth on the surface and core of tonsils was nearly equal (62\% and $63 \%$ respectively). An equal incidence of surface and core isolates was seen in three studies; ${ }^{4,11,12}$ whereas in three other studies, core isolates were nearly double that of surface isolates..$^{13,14,15}$ The lack of any growth in tonsillar surface and core in the rest of the patients could be explained by a possible role of viruses in precipitating chronic tonsillitis, which has not been investigated in our study. It could also be attributed to the fewer number of attacks of tonsillitis in those patients. Staphylococcus aureus was the commonest isolate from both surface and core of tonsils. Streptococcus pyogenes was the next common isolate from the core. The aerobic isolates of the present study are comparable to findings of some of the previous studies. ${ }^{4,12,16}$

Anaerobic isolates in the surface and core cultures in the present study were almost equal (47\% and $48 \%$ respectively). Another study revealed anaerobic growth in $20 \%$ surface isolates and $62.5 \%$ core isolates. In $61.1 \%$, anaerobes were isolated in both surface and core cultures. Same isolates were seen in $59.1 \%$ in cultures from surface and core. ${ }^{17}$ Porphyromonas sp. was the commonest anaerobic isolate from surface and core in the present study. These findings differ from those of Mitchelmore et al, which showed Fusobacterirum sp. as the commonest organism from the surface and Peptostreptococcus micros from the core. ${ }^{18}$ Bacteroides melaninogenicus was the most common anaerobe isolated from tonsil cores in a study by Reilly and coauthors. ${ }^{19}$ Taylan et al concluded that Peptostreptococcus sp. was the commonest organism in tonsil core (37\%). ${ }^{16}$ In our study, Peptostreptococcus sp. was isolated from surface only.

Same isolates in both surface and core cultures were more common among aerobic group (78\%) than among the anaerobic group of bacteria (45\%). Patients with aerobic growth in tonsil surface as well as core (37) outnumbered patients with anaerobic growth in surface as well as core (29). Polymicrobial aerobic flora was more frequently encountered $(15 \%$ on surface, $16 \%$ in core) when compared with polymicrobial anaerobic flora ( $3 \%$ in surface and $0 \%$ in core). Aerobic and anaerobic isolates together were slightly more in the tonsil core (90\%) and $48 \%$ respectively) when compared to the same in tonsil surface ( $87 \%$ and $47 \%$ respectively).

Further studies are recommended to analyze the possible role of viral etiology and host factors like malnutrition, socio-economic status and poor oral hygiene in the causation of chronic tonsillitis. Also, in view of the fact that tonsillitis is a common condition existing in widespread geographical areas, studies with a greater sample size and over larger geographical regions are recommended. 


\section{Conclusion}

Throat swab adequately represents the core pathogen, and is dependable in detecting the bacteriology of chronic tonsillitis. Staphylococcus aureus and Porphyromonas sp. were the most common aerobic and anaerobic pathogens respectively, among both children and adults.

\section{References}

1. Collee JG, Fraser AG, Marmion BP, Simmons A. Mackie \& McCartney Practical Medical Microbiology. 14th ed. Churchill Livingstone; New York; 1996

2. Sutter VL, Citron DM, Edelstein M, Finegold SM. Wadsworth Anaerobic Bacteriology Manual. 4th ed. Star Publishing Company; California; 1985.

3. Agrawal A, Kumar D, Goyal A, Gupta R, Bhooshan S. Bacteriological evaluation and their antibiotic sensitivity pattern in tonsillitis. IOSR J Dental Med Sc. 2014; 13(3):51-5

4. Bista M, Sinha BK, Amatya RCM, Tuladhar NR, Pokharel BM. Comparison of core and surface cultures in recurrent tonsillitis. J Institute Med. 2005; 27:60-5

5. Kumar A, Gupta V, Chandra K, Gupta P, Varshney S. Clinico bacteriological evaluation of surface and core microflora in chronic tonsillitis. Ind J Otolaryngol Head Neck Surg. 2005; 57(2):118-20

6. Mallya PS, Abraham B. Clinico Microbiological Evaluation of Surface and Core Microflora in Chronic Tonsillitis. Ind J Otolaryngol Head Neck Surg. 1998; 50(3)281-3

7. Gul M, Okur E, Ciragil P, Yildirim E, Aral M, Kilic MA. The comparison of tonsillar surface and core cultures in recurrent tonsillitis.Am J Otol. 2007; 28(3):173-6

8. Jayasimha VL, Vinodkumar CS, Raghukumar KG, Basavarajappa KG. Surface Tonsillar bacteria versus deep tonsillar bacteria in tonsillitis. J Pub Health Med Res. 2013;1(2):92-4
9. Brodsky L. Modern assessment of tonsils and adenoids. PedClin North Am. 1989 ; 36(6):1551-69

10. Hadi U, El-Hajj M, Uwaydah M, Fuleihan N, Matar GM. Characteristics of Pathogens Recovered from the Tonsils and Adenoids in a Group of Lebanese Children Undergoing Tonsillectomy and Adenoidectomy.J Applied Research. 2005; 5(3):473-80

11. Shishegar M, Ashraf MJ. Post-tonsillectomy Bacteremia and Comparison of Tonsillar Surface and Deep Culture. Adv in Prev Med. 2014;1-5

12. Babaiwa UF, Onyeagwara NC, Akerele JO. Bacterial tonsillar microbiota and antibiogram in recurrent tonsillitis. Biomedical Research 2013; 24:298-302.

13. Pereira LMP, Juman S, Bekele I, Seepersadsingh N, Adesiyun AA. Selected bacterial recovery in Trinidadian children with chronic tonsillar disease. Rev Bras Otorrinolaringol. 2008; 74(6):903-11

14. Al-Roosan M, Al-Khtoum N, Al-Said H. Correlation between surface swab culture and tonsillar core culture in patients with recurrent tonsillitis. Khartoum Medi J. 2008;1(3):129-32

15. Yousef RY, Faza'a SA, Yousef RY. Comparison of The Bacteriology of Tonsil Surface and Core in Bacterial Profile Isolated from Children with Chronic Tonsillitis. Med J Babylon. 2014; 7(1):52-7

16. Taylan I, Ozcan I, Mumcuoglu I, Baran I, Ozcan KM, Akdogan O, Selcuk A, Balaban N, Dere H. Comparison of the surface and core bacteria in tonsillar and adenoid tissue with betalactamase production. Ind J Otolaryngol Head Neck Surg. 2011;63(3):223-8

17. Klug TE, Henriksen JJ, Fuursted K, Ovesen T. Similar recovery rates of Fusobacteriumnecrophorum from recurrently infected and non-infected tonsils. Dan Med Bull. 2011; 58(7):1-5

18. Mitchelmore IJ, Reilly PG, Hay AJ, Tabaqchali S. Tonsil surface and core cultures in recurrent tonsillitis: Prevalence of anaerobes and beta-lactamase producing organisms. Eur J Clin Microbiol Infect Dis. 1994;13(7):542-8

19. Reilly S, Timmis P, Beeden AG, Willis AT. Possible role of the anaerobe in tonsillitis. J Clin Pathol. 1981;34:542-7. 


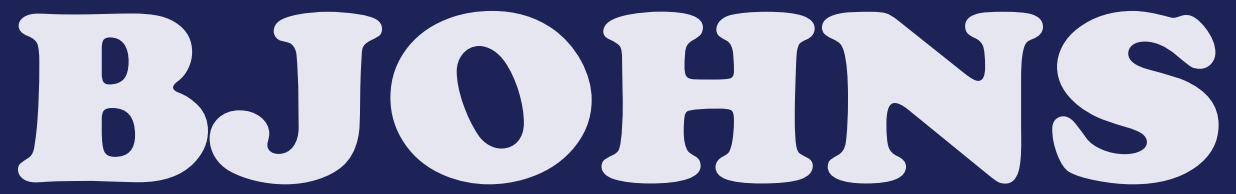

\section{Bengal Journal of Otolaryngology and Head Neck Surgery}

The Official Publication of The Association of Otolaryngologists of India, West Bengal

\section{NOW ONLINE at www.bjohns.in}

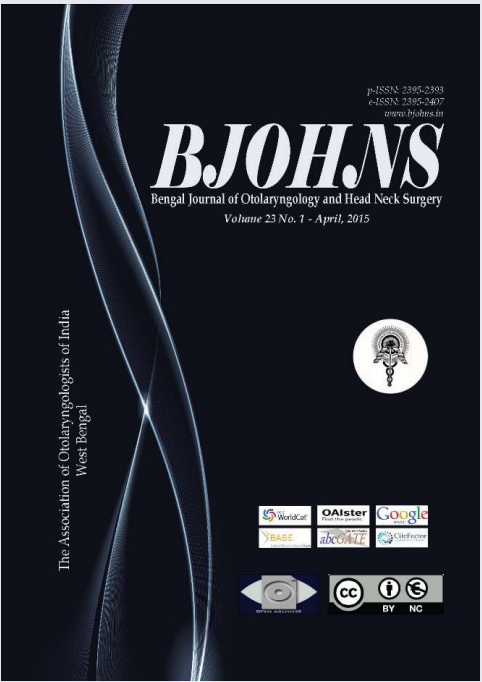

EASY ONLINE SUBMISSION OF ARTICLES

DOUBLE-BLIND PEER REVIEW PROCESS

ZERO SUBMISSION AND PUBLISHING CHARGES

PUBLISHED IN PRINT AND ONLINE VERSIONS

INDEXED IN POPULAR INDEXING SERVICES

OPEN ACCESS PROVIDED FOR ALL READERS

\section{FOR AUTHORS}

1. Visit www.bjohns.in on your internet browser (BJOHNS recommends Google Chrome or Mozilla Firefox)

2. Click 'Submit Article' under Publish with Us from the right navigation bar

3. Registered users can $\log$ in to the system with their passwords

4. New users must complete a one-time Registration Process by selecting 'Not a user? Register with this site'

5. Follow the instructions for the easy 5-step submission process

6. Track the status of your submission online as it is processed

\section{FOR READERS}

1. Visit www.bjohns.in on your internet browser (BJOHNS recommends Google Chrome or Mozilla Firefox)

2. Prior registration is not mandatory to browse articles but is preferred as all users are notified about new issues

3. Readers can access all articles published in the journal absolutely free of charge

4. Select 'Current' for the current issue and 'Archives' for previous issues from the top navigation bar

5. Use 'Article Tools' from the right navigation bar to cite the article, email the article hyperlink to a colleague or contact the corresponding author by email 